\title{
Hybridity Revisited: Relational Approaches to Peacebuilding in Complex Sociopolitical Orders
}

\author{
Charles T. Hunt ${ }^{1}$
}

\section{Introduction}

In recent years, hybridity has received a great deal of attention in the peacebuilding and development literature. This 'rediscovery' of a concept with strong roots in critical and postcolonial theory ${ }^{2}$ has emerged in critical peace studies as a compelling lens with which scholars can better understand the empirics of sociopolitical order and the forms of peace produced through international interventions in conflict-affected states. To a growing extent, these formulations are beginning to find their way into the documents, frameworks and even practices of the organisations who design and implement policy in these areas. ${ }^{3}$ Notwithstanding its appeal and traction, hybridity has come in for a range of critiques regarding its content as well as its use in both scholarship and praxis. Some have cautioned about the risk of instrumentalisation in practice while others have identified potential ethical and political implications associated with

1 The work for this chapter was supported by a grant under the Australian Development Research Awards Scheme (DFAT agreement 66442).

2 Bhabha, The Location of Culture.

3 See, for example, World Bank, World Development Report 2011. 
its (mis)use. Of particular interest here, hybridity has also been subject to criticism for its perceived ontological and epistemological biases manifest in the persistence of reductive analytical binaries and a preoccupation with entities over and above the relationships between them.

This chapter picks up on these critiques, and argues for an augmented concept of hybridity that embraces a relational approach to the theory and practice of peacebuilding and development. I argue that such an approach to understanding and working with conflict-affected societies provides a means to overcome the biases that hybrid approaches can produce. The chapter begins by articulating the nature of hybrid sociopolitical order in many conflict-affected societies and outlines the salient criticisms directed at the hybridity concept. It then proposes a relational account of multilayered sociopolitical order. Drawing on examples from fieldwork and research in Liberia, I identify the value that a relational approach could bring to the concept of hybridity in understanding and working in complex adaptive systems. The final section reflects on how an analytical framework informed by these conceptual moves can handle perceived deficiencies in hybridity relating to treatment of power relations, dynamics, and notions of space and territoriality in conflict-affected societies.

\section{Hybrid sociopolitical orders, binaries and blind spots}

In keeping with a number of other chapters in this volume, ${ }^{4} \mathrm{I}$ argue that empirical pluralism characterises the provision of governance, security and justice in the majority of the world's conflict zones. In postcolonial states of sub-Saharan Africa in particular, social order is the product of the work of myriad actors who provide critical services and ultimately contribute to the formation of political community and social peace. When it comes to everyday public safety, dispute resolution and community harmony, the institutions of government such as the national police, courts and corrections facilities play an important role in this regard. However, they are at most only part of the plural security and justice landscape.

4 Such as Boege, Brown, etc. 
What Ostrom calls 'polycentric governance' connotes an order (or more accurately a system of overlapping/intersecting orders) where these government institutions are often complemented by a range of societal bodies that are deeply involved in providing for the everyday needs of the majority of people. ${ }^{5}$ This cast of players does not fit neatly into any single umbrella category such as Western notions of civil society. ${ }^{6}$ For instance, while this often includes traditional authorities and autochthonous agencies such as chieftaincies and councils of elders, it also stretches to incorporate providers such as citizen militia groups and private security forces as well as less obviously coercive elements such as trade unions, private-sector entities and more community-based—occasionally 'secret'—societies. ${ }^{7}$

Local populations often favour this collection of actors providing conflict management and social services beyond the strict purview of central government. This can be for a combination of reasons related to access, cost, timeliness and cultural sensitivity. Ultimately, these preferences translate into high(er) levels of public familiarity and trust. ${ }^{8}$ Recent studies reinforce the empirical reality that in conflict-affected states security and justice needs are addressed through these means for the majority of people most of the time. ${ }^{9}$ While this is often generalised to be a rural or 'hinterland' phenomenon, similar patterns pertain in urban spaces where, despite displacement and heterogeneity, authority and legitimacy remain multifaceted.

The result is fundamentally different systems of social and political ordering. This sits in stark contrast to a Weberian ideal type where the statenarrowly defined-possesses a rational bureaucracy and holds (or at least claims) a monopoly on the legitimate recourse to violent means to retain order. These multilayered systems operate according to different logics of governance whereby legitimacy is derived from a range of sites and the construction of authority is a dynamic process. ${ }^{10}$ This plethora of providers inhabits what is, in effect, a hybrid sociopolitical order that emerges from the intricate interactions across this assortment of actors. ${ }^{11}$

\footnotetext{
5 Ostrom, 'Polycentricity (Parts 1\&2)'.

6 Richmond and Mitchell, 'Introduction-Towards a Post-liberal Peace', 13.

7 Raeymaekers et al., 'State and Non-state Regulation in African Protracted Crises', 8.

8 Baker and Scheye, 'Multi-layered Justice and Security Delivery', 512.

9 OECD-DAC, 'Improving Security and Justice Programming', 22, fn15. See also Albrecht and Kyed, 'Introduction: Non-state and Customary Actors'.

10 Boege, 'Legitimacy in Hybrid Political Orders', 10-12; Boege et al., Addressing Legitimacy Issues in Fragile Postconflict Situations.

11 Boege et al., On Hybrid Political Orders and Emerging States.
} 
In recent years, a growing number of critical peace and security scholars have embraced 'hybridity', championing its conceptual and explanatory potential for informing analysis of conflict-affected societies. ${ }^{12}$ More recently, the language and ideas around hybridity have begun to appear in policy documents and programs aimed at building peace and supporting development in so-called fragile states. ${ }^{13}$ However, despite its growing popularity, efforts to apply concepts of hybridity to the analysis of these settings have met with a number of critiques. ${ }^{14}$ Among other things, the normative intent of hybridity or scholars who promote it has been challenged. ${ }^{15}$ This in turn has precipitated debates in the literature over inconsistent and divergent applications and the relative opportunities and challenges associated with descriptive, prescriptive and instrumental applications of hybridity. ${ }^{16}$ Notwithstanding the central ethical, political and practical dilemmas these debates throw up, a range of criticisms has also emerged that relate to the ontological and epistemological orientations of hybridity.

First, some scholars have argued that hybridity models perpetuate the reification of arbitrary categories. Efforts to understand the plural nature of security and justice provision in conflict-affected societies tend to categorise providers as 'one' or 'other' in a coterie of analytical binaries. It is common for particular agents to be described as state or non-state, formal or informal, traditional or modern, or local or international. Furthermore, it is often implicit that these dichotomies map to ideas of actors operating in spaces or ways deemed to be licit versus illicit or liberal as opposed to illiberal. This is more than a semantic issue as the use of these labels can generate significant ethical, political and practical challenges.

12 See, for example, Boege et al., 'Building Peace and Political Community'; Mac Ginty, International Peacebuilding and Local Resistance; Richmond and Mitchell, Hybrid Forms of Peace.

13 For example, DFID, Policy Approach to Rule of Law; World Bank, World Development Report 2011.

14 For extended discussion of critiques, see Kent et al., 'Introduction', this volume.

15 See, for example, Cassani, 'Hybrid What? Partial Consensus and Persistent Divergences'; Chandler, 'Peacebuilding and the Politics of Non-linearity'; Heathershaw, 'Towards Better Theories of Peacebuilding'; Meagher, 'The Strength of Weak States?'; Nadarajah and Rampton, 'The Limits of Hybridity'.

16 See, for example, Brown, this volume; Forsyth, this volume; Mac Ginty and Richmond, 'The Fallacy of Constructing Hybrid Political Orders', 224-228; Millar, 'Disaggregating Hybridity'; Wallis et al., 'Political Reconciliation in Timor Leste', 162. 
Proponents argue that hybridity can provide the conceptual framework necessary to transcend and do away with analytical binaries. ${ }^{17}$ For instance, Mac Ginty and Richmond argue 'the concept of hybridity, if used as a post-colonial, post-territorial and post-biological construct, liberates us from the dominant policy script of goodies and baddies, states and non-states and West and non-West'. ${ }^{18}$ However, others argue that efforts to develop the utility of hybridity in understanding fragile/conflictaffected societies-particularly where it has appeared in peacebuilding and development policies and praxis-have actually served to 're-inscribe' these binaries. ${ }^{19}$ For example, Moreiras argues that despite good intentions hybridity literature has a tendency to fall back on problematic binaries to describe and understand the roles and influence of the different providers involved in the production of order. ${ }^{20}$ The malignance of this dichotomous version of reality can have a number of negative consequences. ${ }^{21}$

It is true that binary categories are difficult to avoid when analysing different types of actors. Indeed, these categorisations can perform some useful function when conducting analyses. For example, drawing boundaries around different nodes of providers of social order can help in the process of identifying relationships between them. ${ }^{22}$ However, it has been argued that one of the downsides of continued use of such analytics is uncritically essentialising and/or romanticising actors deemed to be autochthonous or local, underplaying the ethical and accountability issues associated with their function. ${ }^{23}$ This approach invariably focuses on what qualities and characteristics distinguish providers from each other and risks exaggerating the veracity of the dichotomies. ${ }^{24}$

17 Boege, this volume; Peterson, 'A Conceptual Unpacking of Hybridity', 12. See originally Mac Ginty, 'Hybrid Peace: The Interaction between Top-Down and Bottom-Up Peace'; Mac Ginty, 'Hybrid Peace: How Does Hybrid Peace Come About?'.

18 Mac Ginty and Richmond, 'The Fallacy of Constructing Hybrid Political Orders', 220.

19 Hameiri and Jones, this volume. See also Heathershaw, 'Towards Better Theories of Peacebuilding', 277; Laffey and Nadarajah, 'The Hybridity of Liberal Peace', 417; Sabaratnam, 'Avatars of Eurocentrism', 261-263.

20 Moreiras, 'Hybridity and Double Consciousness'.

21 Bliesemann de Guevara, 'Introduction: The Limits of Statebuilding'; Heathershaw, 'Towards Better Theories of Peacebuilding; Millar, 'Disaggregating Hybridity'; Peterson, 'A Conceptual Unpacking of Hybridity'.

22 The author is grateful to the editors for this point.

23 Bliesemann de Guevara, 'Introduction: The Limits of Statebuilding'; Meagher, 'The Strength of Weak States?'; Peterson, “'Rule of Law” Initiatives'.

24 See also Ojendal et al., 'The "Local Turn" in Peacebuilding'; Randazzo, 'The Paradoxes of the "Everyday". 
Second, and related to this endurance of analytical binaries, hybridity has met with criticism for being problematically reductive in the way it accounts for the construction of authority and the production of order. For instance, Dirlik states 'hybridity reduces all complexity to a "statement of mixture" and goes on to problematise the fact that this leaves out some of the specifics of what is being mixed..$^{25}$ Moreover, by depicting complex social order as a 'mixture' of agency, a hybridity lens can oversimplify or obscure how this 'mixing' occurs and exactly how (and what sort of) sociopolitical order emerges. As a result, hybridity has faced criticism for being undertheorised, ${ }^{26}$ failing to reveal power dynamics, ${ }^{27}$ underplaying the perpetuity of change, and being inadequate for handling different territorialities/levels of analysis. ${ }^{28}$ By extension, this critique contends that such an approach can also mask the potential for malevolent emergence and hybrid outcomes. ${ }^{29}$ Consequently, it is argued that imprecision may limit the utility of hybridity for explaining how (dis)order emerges and evolves over time.

These criticisms point to a problematic focus on actors and their features at the expense of seeking out how myriad providers are linked, the ways in which they relate, and how they are at times intrinsically dependent on each other to achieve their objectives. The allegation is therefore that hybridity's analytical imprecision renders the empirical relationships between these actors underexamined and often misunderstood..$^{30}$ Where hybridity literature does elevate the relationships between key actors, it tends to focus primarily on the interface between the 'international' and the 'local' or Western and non-Western actors. ${ }^{31}$ The preoccupation in the hybridity literature with this particular encounter inhibits a more nuanced rendering of the relationships between all providers at multiple levels across the system, particularly those between inhabitants in the local sphere. ${ }^{32}$

25 Dirlik, 'Bringing History Back In', 106.

26 Millar, 'Disaggregating Hybridity', 501.

27 Meagher, 'The Strength of Weak States?', 1078; Peterson, 'A Conceptual Unpacking of Hybridity',

14; see also Pieterse, 'Hybridity, So What?'; Tanikella, 'The Politics of Hybridity'.

28 See, for example, critiques of Mac Ginty's 2011 hybridisation model by, inter alia, Millar.

29 Meagher, 'The Strength of Weak States?', 1073.

30 Frödin, 'Dissecting the State', 271.

31 Sabaratnam, 'Avatars of Eurocentrism', 269.

32 Paffenholz, 'Unpacking the Local Turn in Peacebuilding'. 
In order to accurately reflect complex forms of social (dis)order in conflict-affected societies our conceptual and analytical tools need to be as agile and dynamic as the systems we seek to track and understand. However, as a result of the aforementioned shortcomings, current uses of the concept of hybridity struggle to apprehend the nuanced, mutable and context-specific relationships between a diverse array of providers of governance, security and justice. The following section turns to insights from complexity theory in order to develop a more relational focus in the application of hybridity.

\section{Complex social order and a primacy of relationships}

The hybrid sociopolitical orders described above display the characteristics of a complex social system. According to complexity theory, a social system (society) is 'complex' if it displays the following features and properties. Interacting parts of the system produce intricate interdependence between constituent elements. This dictates that the actions of one part of the system can impede another or indeed the whole system. The interactions are changing and it is the degree of 'connectivity' (i.e. interdependence) that controls how change occurs through the system. This contingency produces feedback processes that can drive or inhibit system change. It is through this feedback that properties and behaviours at the system level are relayed to their original source and other elements of the system. This in turn causes often unpredictable outcomes known as the emergent properties - that is, the behavioural patterns of the system as a whole. Emergence is therefore contingent on and produced by the myriad of possible interrelationships between elements within the system. This emergence is difficult to predict based on the characteristics of constituent parts and the archetypal feature of a complex system. ${ }^{33}$

These particular characteristics dictate that change in system-level outcomes occurs in three key ways. First, change occurs in a nonlinear fashion where outcomes are not directly proportionate to variations in the inputs and resources available. ${ }^{34} \mathrm{~A}$ multiplicity of influencing factors means that causal relationships are difficult to identify and cannot be

34 Stacey, Complexity and Creativity in Organizations, 23-28, 65. 
assumed. Second, adaptive agents comprise the complex social system and as conscious agents have the ability to 'know' and adjust their behaviour according to information gleaned and lessons learned. This means that, as a result of human agency, complex social systems have an intrinsic capacity to self-organise. ${ }^{35}$ Consequently, and third, they are in a continuous process of coevolution in relation to each other as well as to the broader systemic environment, reproducing along trajectories that are influenced but never fully determined by any one of a large number of factors. ${ }^{36}$ In this reading of the context, it is the relationships between providers of security and justice that are constitutive of emergent order. Therefore, to understand how hybrid (dis)order emerges requires a more nuanced understanding of the type of relationships between providers more than a deep grasp of the features of the providers in a complex social system.

In hybrid orders, the whole gamut of providers are interacting and evolving in relation to each other. As Albrecht and Kyed have argued, 'there may be full recognition and close collaboration, limited partnership, unofficial acceptance, competition and even open hostility'. ${ }^{37}$ It is these relationships that generate the entanglements symptomatic of hybridity and generative of emergent sociopolitical order. The next section uses examples from the case of Liberia in West Africa to elaborate on the range of relationships at play.

\section{Complexity in practice: The case of Liberia}

The relationships between the institutions of central government and a range of other providers of security and justice in a hybrid order are often explained in terms of competition..$^{38}$ For instance, Charles Taylor's armed insurrection through the 1990s is perhaps more clearly understood as a predatory zero-sum battle with the sovereign government it sought to overthrow. However, both were fundamental to providing basic public goods and social order (such as it was) in the territories they controlled. In this case, a warlord controlling strategic locations and trade routes was viewed as a threat by a central state bunkered and restricted to an isolated urban capital in Monrovia. The central government's efforts to extend

35 Heylighen, The Science of Self-organization and Adaptivity, 4-5.

36 Garnsey and McGlade, Complexity and Co-evolution.

37 Albrecht and Kyed, 'Justice and Security', 2.

38 Bayart et al., The Criminalization of the State in Africa. 
its authority over the national sovereign territory also clearly constituted a threat to Taylor's authority. Actors whose authority is contingent on different sources and logics can at times directly contest each other for political capital and resources.

However, there is invariably a good deal more interdependence and cooperation between government and a range of other actors. Accommodation here can be both formal and more informal but the nature and content of these relationships are vital in the co-production of order. ${ }^{39}$ For example, in rural Liberia, where government institutions do not reach or would not be well tolerated, societal bodies such as councils of elders or secret societies often provide essential services. ${ }^{40}$ Chiefs, for instance, are commonly seen as a significant authority in the community, drawing on customary sources of legitimacy. However, through statesponsored customary law they also play a role in the formal dual legal system and consequently lend significant support to central government in the production of order. ${ }^{41}$ Furthermore, delineations of statutory and customary law or rules are not strictly adhered to in practice. Customary courts are constitutionally empowered to handle civil but not criminal cases; however, this division of labour is not always adhered to. In effect the central government is dependent on community-based actors for maintaining everyday social order.

Similarly, vigilantes, citizen militia or 'community watch groups' are ubiquitous across Liberia. ${ }^{42}$ While such entities are often understood as challenging the state's monopoly on legitimate violence, they have also proven to be a vital source of providing protection and defence of towns and communities. ${ }^{43}$ Moreover, the relationship between the Liberian National Police and these groups has ranged from tacit acquiescence to formal approval, partnership and even the provision of training and material support.

39 Baker, Security in Post-conflict Africa, 32-35.

40 Reports from focus groups and key participant interviews conducted as part of fieldwork for author research project 'Understanding and Working with Local Sources of Peace, Security and Justice in West Africa' (Australian Government Department of Foreign Affairs and Trade). See also Jaye, Understanding and Explaining Hybridity.

41 Lubkemann et al., 'Justice in a Vacuum'.

42 Kantor and Persson, Understanding Vigilantism.

43 Isser et al., Looking for Justice. 
In these cases, entities conventionally thought of as non-state or informal can behave in very 'state-like' ways. The central government not only tolerates their conduct but by outsourcing service provision to them affords a certain degree of legitimacy to these actors. In these cases, the relationships between state institutions and societal bodies can be mutually beneficial. Accurate recognition of this variation in relationships across state and non-state providers is critical to analysts and peacebuilders for a number of reasons. First, this elaborates the degree of hybridisation that has already occurred and led to current conditions. Second, a more accurate grasp of cooperation as well as competition between these stakeholders feeds understanding of the nature of emergent everyday peace and security.

Those providers who do not derive authority directly from the writ of the state will also have a diverse range of relationships among them. These, too, matter fundamentally to the everyday experiences of (dis)order. For instance, in Liberia, the relationships between town, quarter, clan and village chiefs can often be discerned through known hierarchies and territoriality. However, the way that these same chiefs relate to other elders in their community, secret societies such as the Poro, and those who are deemed to have access to the ancestral realm (e.g. juju men) is less visible but no less important to the way in which order is sustained. ${ }^{44}$ Similarly, in the settlement of disputes at the local level, resolution may depend on a network of actors. For instance, a town chief may not be able to pass judgement on a dispute unless the witch doctor is able to remove a curse from one of the disputants. ${ }^{45}$ The satisfactory settlement is contingent on a range of functional relationships among a number of societal actors. ${ }^{46}$ It is the unique way in which theses interactions occur that produces an outcome and contributes to emergent order.

During Liberia's civil war there was a struggle for authority between some of the elders and those participating more actively in the fighting. In particular, youth who became empowered through membership of militia challenged the traditional gerontocratic structures of society. ${ }^{47}$ This obviously had a significant impact on people’s everyday security during

44 Focus group report from fieldwork in Liberia, Australian Development Research Awards.

45 Herman and Martin-Ortega, 'Narrowing Gaps in Justice', 146; Lubkemann et al., 'Neither State nor Custom'. See also Ellis, The Mask of Anarchy, 225.

46 Flomoku and Reeves, 'Formal and Informal Justice in Liberia'.

47 Sawyer, 'Social Capital, Survival Strategies, and Their Potential for Post-conflict Governance in Liberia'. 
the years of conflict. However, to this day, the relations between chiefs, elders and ex-combatants-demobilised and reintegrated into society to varying degrees - continues to shape the contours of everyday order. ${ }^{48}$

While Liberia is only a single case and the above discussion is far from exhaustive, it bears a strong resemblance to other conflict-affected societies in West Africa—neighbouring Sierra Leone and Côte d'Ivoire. ${ }^{49}$ Furthermore, these relational dynamics can be seen as emblematic of a wider set of postcolonial states emerging from violent conflict where peacebuilding efforts have been attempted and met with mixed results. Emphasising the importance of relationships between providers may seem common sense. However, such recognition eludes extant mainstream thinking and praxis around peacebuilding — focused, as it overwhelmingly is, on ontological questions of what entities exist and their characteristics rather than how all pertinent entities interrelate and co-produce order. This risks overlooking the forms of peace that emerge as the result of feedback between intertwined providers. Moving beyond a taxonomy of providers, it is the nature of the linkages between myriad providersirrespective whence they derive their legitimacy or authority-that is central to emergent (dis)order. Therefore, in keeping with some recent developments in the peacebuilding literature, ${ }^{50} \mathrm{I}$ argue that what is needed is a relational approach when articulating hybrid forms of peace and order.

\section{Operationalising a relational approach}

Translating and working in line with a relational approach requires new and tailored conceptual tools. These can take the form of theoretical but also analytical frameworks. One such analytical framework based on these ideas has been developed elsewhere by this author. ${ }^{51}$ The framework elaborates on a set of 'symbiotic relations' between myriad providers of social order. Borrowed from biology, symbiosis refers to the state of entities 'living together'. The framework explains three categories. The first, predatory-amenalism, incorporates confrontational relationships between providers. The second, commensalism/parasitism, includes relationships

\footnotetext{
48 Focus group report from fieldwork in Liberia, Australian Development Research Awards.

49 Fawole and Ukeje, The Crisis of the State and Regionalism in West Africa.

50 See, for example, Brigg, 'Relational Peacebuilding'. See also Gadinger et al., Relational Sensibility and the 'Turn to the Local'.

51 Symbiosis framework developed in Hunt, 'Beyond the binaries'.
} 
between providers characterised by sustainable asymmetry. The third, mutualism, refers to those relationships that are characterised by mutual benefit and 'complementarity'. These categories capture the ways in which relations embody a continuous process of contestation, accommodation or outright cooperation in the construction of authority and distribution of resources.

The framework categories allow the multiverse of connectivities and subtleties of interaction to be more accurately depicted. In doing so, this approach offers a corrective to three substantive criticisms of extant models of hybridity and hybridisation. ${ }^{52}$ First, these bonds are not fixed nor meant to imply rigidity. On the contrary, the systems of sociality at play are dynamical where elements are adapting and evolving in relation to each other as a result of ongoing feedback processes. Alliances are ephemeral and changeable; history and context matter hugely, such that the relationship that applies to particular providers will have multiple potential equilibria and the type of relationship is therefore mutable. The dynamical nature of the system means that relations are shifting and continuously renegotiated-characterised by ongoing processes of exchange between and across different elements of the system. The feedback intrinsic to these relations renders all actors in coevolutionary processes, altered as a result of the interactions and influence on each other such that they cannot be static or unchanging. This leads to a conception of hybrid order that is emergent, self-organised and a dynamic coevolutionary sociopolitical system.

Second, the relations articulated through the framework are imbued with power. That is, the bonds between providers reflect the political economy of power in conflict-affected societies. It is these relationships that therefore shape, empower and at times constrain the extent to which social systems are resilient. The construction of authority is embedded in the relationality revealed through the framework. Any changes to who is providing security and justice services will in turn entrench or redistribute power in significant ways. Far from ignoring or trying to obfuscate questions of power, this framework tackles the aforementioned criticism of hybridity by revealing and integrating rather than concealing and obscuring power dynamics. It supports a more nuanced rendering of power but moreover creates the space for a potentially profoundly different conceptualisation

52 See, for example, the critique of Mac Ginty, International Peacebuilding and Local Resistance, in Millar, 'Disaggregating Hybridity'. 
of power. This promises to better reflect how it is mediated, contested and ultimately shared in the symbiosis at play. Gaining clarity on the circulation of power within the local sphere is a precondition for understanding who has the capacity and resources to interact with international actors in order to be heard and make claims-potentially shaping outcomes through blocking, contaminating or enabling different formations of peace. ${ }^{53}$ It is, nevertheless, important to note that those who are not possessed of visibility and voice are not necessarily without agency or influence. On the contrary, with nonlinear change the norm in complex systems, more detailed articulations of power can also inform more convincing explanations for unpredictable outcomes and modalities better prepared to expect the surprising. This can in turn form a backdrop for subsequent analyses of the hybrid forms of peace that emerge as a result of strategies and tactics of acceptance, hybridisation, co-optation and resistance by locals in the face of international interventions. ${ }^{54}$

Third, and following from above, the framework enables an approach that is not simply about understanding and working with the oftenobscured actors inhabiting the 'local' arena. By opening up questions of relationality, this approach offers a way of understanding the system holistically. This is consonant with the spatial turn in state theory/political geography, bringing in the different levels at which politics takes place and requiring a certain incorporation of the 'politics of scale'. The framework not only allows for assessments of networked relationality across different providers within particular strata but also across providers at different levels. This means that the significance of agency in the local arena can be understood in the context of provincial and national settings. As with the discussion relating to power, this also opens up possibilities for more finely grained analysis incorporating stakeholders at the international and transnational levels. This multilevel and multidimensional approach allows for assessments that ask which, if any, levels and interfaces are most significant in the emergence of (dis)order. ${ }^{55}$

This is all to argue that the plurality of providers of social order and the realms they inhabit do not simply co-exist alongside each other or only interact through unavoidable overlap. On the contrary, they have

53 Richmond, 'The Paradox of Peace and Power'. See also Peterson, 'A Conceptual Unpacking of Hybridity', 17.

54 Richmond and Mitchell, 'Introduction-Towards a Post-liberal Peace', 8-10.

55 For discussion of the relative weight of different interfaces see Debiel and Rinck, 'Rethinking the Local in Peacebuilding'. 
genuinely symbiotic relationships that are constitutive of emergent and hybrid order. The everyday exchanges that occur between providers of services, and between them and 'end users', are actually generative of the agency at play and therefore critical to the imaginary of what constitutes political community for conflict-affected populations as well as its substance and dynamics.

While it is not entirely new to acknowledge the networked nature of providers, ${ }^{56}$ the symbiosis framework discussed here constitutes an example of how a relational approach could be realised in tangible ways that can further inform theorising and praxis relating to hybridity. Such an approach and others like it - grounded in relational understandings of the societies on the receiving end of international intervention-offer the possibility of redressing the lack of empiricism that besets current international efforts to reform and rebuild security and justice sectors in developing and conflict-affected contexts. What is critical is that these tools and analytical frameworks are promulgated in ways that are accessible to researchers and practitioners.

\section{Conclusion}

Overall, the analysis described here contributes to the argument for a relational approach—for a performative-based, liminal and integrative understanding of hybrid sociopolitical order and how this can inform peacebuilding theory and practice. While such a shift presents many opportunities, it also presents ethical, political and practical challenges for research and policy. ${ }^{57}$ It is therefore important to acknowledge that greater understanding of the emergence of everyday order in conflict-affected states can be instrumentalised or co-opted by international peacebuilders, just as those on the receiving end of their interventions can also divert and manipulate the material support brought from the outside. A relational approach could also create rationales to support malevolent emergence that inadvertently empowers entities and practices that propagate rather than transform violent and discriminatory practices.

56 See, for example, Forsyth, 'Spinning a Conflict Management Web in Vanuatu'.

57 See, for example, Chandler, 'Peacebuilding and the Politics of Non-linearity'. 
Notwithstanding the challenges, a relational approach promises to enhance our understanding of the way in which (dis)order emerges in complex social systems affected by conflict. It also provides a way of revealing and conceptualising the agency of people affected by conflict and elaborating on how their everyday experiences are shaped. ${ }^{58}$ It furnishes us with a way of taking seriously the strengths and weaknesses of those processes in the pursuit of peacebuilding objectives. Such an approach requires innovative conceptual tools, such as the symbiosis analytical framework discussed herein, to realise its potential. Rather than attempting to displace hybridity, the relational approach proposed here is intended to extend and augment it. The symbiosis framework and other conceptual tools like it have the potential to bring additional analytical leverage and shed further light on the empirical realities that the hybridity lens already brings to our attention. A framework for analysis based on these insights can help reveal the nature of the multiplicity of relationships among the range of providers of security and justice. It can also point to the significance of these relations in the construction of authority and the production of emergent (dis)order. This may have the potential to enhance the utility of hybridity as a conceptual and analytical tool for both scholars and practitioners of peacebuilding. Doing so should help us move beyond the deployment of limited and limiting binaries that do not stand up to scrutiny, underplay the nuance and variation of the relations between providers, and fundamentally miss how (dis)order emerges in the complex social systems pertaining in conflict-affected societies. As well as better tools, such a relational approach demands more humble, realistic and pragmatic expectations from the advocates and agents of peacebuilding about what can be achieved and in what time frame. This is in keeping with calls for 'slower and more open processes' that are 'dialogical and organic' while 'patient and sensitive to different temporal sensibilities. 59 Moves in that direction may also contribute to opening up discourse and our imaginaries of political community that can in turn offer ways of escaping the teleological visions for the 'state' that dominate current orthodoxy in peacebuilding.

58 Bleiker, 'Conclusion—Everyday Struggles for a Hybrid Peace', 300-303.

59 Comments made, respectively, by Damian Grenfell, Anne Brown and Volker Boege (all contributors to this volume) during the workshop that led to this book. 
This text is taken from Hybridity on the Ground in Peacebuilding and Development: Critical Conversations, edited by Joanne Wallis, Lia Kent, Miranda Forsyth, Sinclair Dinnen and Srinjoy Bose, published 2018 by ANU Press, The Australian National University, Canberra, Australia.

doi.org/10.22459/HGPD.03.2018.03 